\title{
Chromosomes Count, Care Confuses
}

John P. Wattis

D. St Clair, Genetics of Alzheimer's disease: some molecular understandings of a diverse phenotype. British Journal of Psychiatry, 164, ( I 994), 153-1 $5^{6}$.

M. Owen, M. Liddell and P. McGuffin, Alzheimer's disease: an association with apolipoprotein $\mathrm{E}_{4}$ may help unlock the puzzle. British Medical Journal, 308, (1 994), 672-673.

R. M. Kammerling and S. O'Connor, Unemployment as a predictor of rate of psychiatric admission. British Medical Journal, 308, 672-673.

J. Warden, The lottery of long term care. British Medical Journal, 308, (1994), 742 .

There are many kinds of knowledge. One of the paradoxes for a doctor with an interest in social science is the different ways in which we treat 'hard' scientific knowledge and 'softer' social sciences knowledge. During I994, a series of papers were published in The Lancet and elsewhere about the role of apolipoprotein $\mathrm{E}_{4}$ in the genetics of late onset Alzheimer's disease. Scientifically it was very exciting, as referred to in the BMJ editorial and British Journal of Psychiatry review cited above. Briefly, the conclusions of these two papers are that some form of genetic susceptibility is probably a necessary but not sufficient cause of Alzheimer's, and that a variety of chromosomal linkages have been established in Alzheimer's disease. The most recent of these has been to a site on chromosome I9 which codes for variants of a protein called apolipoprotein E. A particular variant, Apolipoprotein $\mathrm{E}_{4}$, is associated with an increased risk of Alzheimer's disease (and also probably vascular disease). Like other genetic 'causes' of dementia it is, in itself, neither necessary nor sufficient. The combined risk of Alzheimer's and vascular dementia is probably only $65 \%$ at age 85 years for an $\mathrm{E}_{4}$ homozygote (effectively someone with a very rare 'double dose' of genetic susceptibility).

It is less the science than the reaction to the science that interests me. Suddenly there is even more interest in the genetics of Alzheimer's disease: more research money is called for. If we do succeed in finding genetic 'markers' for Alzheimer's disease we will be faced with the same kind of dilemma that now prevails with Huntingdon's chorea and other genetically determined disorders. Until a cure is available, will people wish to have a precise estimation of personal risk of developing Alzheimer's disease? Despite these (and other) ethical and practical problems, the push for knowledge is unrestrained.

On the other hand, the reports of our irrational approach to long- 
term care, or of how important non-medical factors like unemployment are to the prevalence of mental illness, do not generate such a thirst for knowledge. Despite the fact that the relationship between deprivation and illness has been known for years, there has been little practical inclination to apply this knowledge. Kammerling et al. show unemployment to be an extremely powerful indicator of the rates of serious mental illness that will need hospital treatment in people under 65 years of age, and they plead for this to be considered in resource allocation. The variation of psychiatric problems with unemployment is much greater than in other areas of ill health. The lack of action in this area is surprising even though the problem of employment is complicated.

Inaction in sorting out the mess in 'the lottery of long term care' is much harder to justify. The report in the $B M J$ concerns the case of a man who was severely brain-damaged by stroke. The Parliamentary Ombudsman had ruled that the National Health Service should have continued to provide care free-of-charge. This focused attention on the general issue of NHS responsibility for people with chronic conditions. The $B M \mathcal{J}$ report states, 'Government policy is more pragmatic than principled. For the million people currently on the NHS waiting list the only question is when they will get the free treatment they need. For the million elderly people aged over 80 years it is already a question of whether they will get the free care they need' (my emphasis).

Thus with apparently 'hard' medical knowledge there is a rush to capitalise on new discoveries even though the practical consequences may be complicated and hard to predict. With 'softer' social knowledge we only seem to be capable of confusion and inaction. As I write an example of a similar dichotomy is highlighted in the media. Six cases of necrotising fasciitis, a rare condition caused by a common bacterium, the haemolytic streptococcus, are in the national news. The Guardian comments that we would be better advised to dedicate effort to reducing smoking and alcohol consumption, with their demonstrated links to illness and death, than to making such a fuss about a 'new killer bug'. Why do people generally ignore important findings in social science and epidemiology whilst enthusing over anything 'medical' or 'scientific' (in a very limited sense of that word)?

Newsam Centre,

Seacroft Hospital, Leeds $\mathrm{LS}_{1} 46 \mathrm{UH}$. 